PAPER

\title{
Stroke in Devon: knowledge was good, but action was poor
}

\author{
C Carroll, J Hobart, C Fox, L Teare, J Gibson
}

J Neurol Neurosurg Psychiatry 2004;75:567-571. doi: 10.1136/jnnp.2003.018382

See end of article for authors' affiliations

.....................

Correspondence to:

Dr C Carroll, Department of Neurology, Derriford

Hospital, Plymouth PL6 8DH, UK; camille.carroll@ pms.ac.uk

Received 8 May 2003

In revised form

30 July 2003

Accepted

10 September 2003

\begin{abstract}
Background and aim: Effective implementation of early treatment strategies for stroke requires prompt admission to hospital. There are several reasons for delayed admission. Good awareness should facilitate early admission. We identified local targets for education.

Methods: Four groups, each of 40 people, completed questionnaires to determine their knowledge of stroke symptoms and risk factors, and the action they took or would take in the event of a stroke. The groups were: patients with a diagnosis of stroke or TIA (within $48 \mathrm{hrs}$ of admission); patients at risk of stroke; the general population; and nurses.

Results: Forty per cent of stroke patients identified their stroke. Median time from onset of symptoms to seeking medical help was 30 minutes. Medical help was sought by the patient themselves in only $15 \%$ of cases. In $80 \%$ of cases the GP was called rather than an ambulance. Of the at risk group, $93 \%$ were able to list at least one symptom of acute stroke, as were $88 \%$ of the general population. An ambulance would be called by $73 \%$ of the at risk group in the event of a stroke. Patients with self reported risk factors for stroke were largely unaware of their increased risk. Only $7.5 \%$ of at risk patients acquired their stroke information from the medical profession.

Conclusions: Public knowledge about stroke is good. However, stroke patients access acute services poorly. At risk patients have limited awareness of their increased risk. A campaign should target people at risk, reinforcing the diagnosis of stroke and access to medical services.
\end{abstract}

$\mathrm{E}$ arly admission to hospital is critical for the effective implementation of early treatment strategies for stroke, ${ }^{12}$ which have been shown to reduce morbidity and cost associated with the condition. ${ }^{3}{ }^{4}$ Nevertheless, there is often a significant delay in patients with stroke reaching hospital. ${ }^{5-8}$ This delay has three components: ${ }^{9}$ appraisal delay, the time from noticing a symptom to deciding one is ill; illness delay, the time from onset of symptoms to seeking professional help; and utilisation delay, the time from seeking professional care to arrival at the hospital.

Several public education campaigns have successfully increased the level of stroke knowledge. ${ }^{10}$ While it is assumed that good stroke knowledge results in faster access to medical services, this link has not been proven. ${ }^{911-14}$

This study had two aims. Firstly, we identified factors governing delay in admission to hospital that could be the focus for education. Secondly, we determined education opportunities that are currently being missed. This study focused on less disabled patients, as patients with severe strokes are admitted sooner than those who are less disabled..$^{15}$

\section{METHODS}

The study was undertaken at Derriford Hospital in Plymouth, England. Four groups were studied:

- Patients with a diagnosis of stroke or transient ischaemic attack (TIA), admitted during the previous 48 hours. Exclusion criteria were inability to communicate, impaired consciousness, or a diagnosis of subarachnoid haemorrhage.

- Patients at risk of stroke identified in hypertension, diabetic, and chronic renal failure clinics.

- Members of the general public recruited from Derriford Hospital.

- Medically trained nurses from non-neurological medical wards.
Following statistical advice, the group size was set at 40 , this figure being achievable in a busy neurology unit and sufficient to identify trends and differences between groups that might merit further study. Study days were identified on the basis of practical considerations. Fifteen such days were identified over a 7 month period between December 2001 and July 2002. On study days, all patients admitted during the previous 48 hours with a diagnosis of stroke or TIA were interviewed. Our unit admits all acute neurology patients and routinely admits patients with TIA if they present acutely. There is no difference in the early management of stroke patients compared with patients who have had a TIA. In addition, consecutive at risk patients attending outpatient clinic appointments who were willing to take part in the study were interviewed. All nurses present on a medical ward at the time of the study were also interviewed. Members of the public were recruited from patients and relatives on nonmedical wards and visitors to the hospital restaurant or cafeteria.

Subjects from each group were interviewed using a standardised, structured interview with open ended questions administered by members of the neurology department on identified study days. The Plymouth local ethics committee approved the study.

In stroke patients, appraisal delay was determined by assessing the ability of patients to correctly identify their diagnosis. Illness delay was estimated as time to seeking medical help from the onset of symptoms. The method of seeking medical help was recorded as this influences utilisation delay. ${ }^{8}$ Non-stroke samples were asked to list stroke symptoms. The symptoms of stroke that were accepted as correct were those matching the NINDS criteria. ${ }^{13}$ Perception of stroke as a medical emergency was assessed in the non-stroke samples, as well as the action that would be taken if either they or a family member had suffered a stroke.

All respondents were asked to list three risk factors for stroke. Their own risk factors were determined and whether a member of the medical profession had ever discussed with 
them their increased risk of stroke, as well as other sources of stroke knowledge. Established risk factors were those listed on the Journal of the American Medical Association patient education page, ${ }^{16}$ hypercholesterolaemia, previous stroke/TIA, and history of ischaemic heart disease.

Medically trained nurses were chosen as they were predicted to have an increased knowledge of stroke symptoms and risk factors, and could be used in an education programme.

\section{Data analysis}

The questionnaires were interview administered, therefore the dataset was complete and there were no missing data. Data were analysed in Microsoft Excel and SPSS. Time delays were compared using the two tailed Student's $t$ test. All other comparisons were performed using appropriate non-parametric analyses.

\section{RESULTS}

\section{Demographic data}

A total of 40 people in each group were interviewed. The group of stroke patients was $42 \%$ male, the group of at risk patients 52\% male, the general population group 52\% male, and the nurses group $8 \%$ male. The mean age (SD) was 70.9 (12.8) years for the stroke patients, 68.2 (12.1) for the at risk patients, 54.4 (19.2) years for the general population, and 38.9 (8.7) years for the nurses.

\section{Knowledge of stroke in the non-stroke groups}

Most people in the three non-stroke groups were able to list at least one stroke symptom (at risk: $92.5 \%$ (CI 8.2); general population: $87.5 \%$ (CI 10.2); nurses: $100 \%$ (CI 0)). Medically trained nurses listed significantly more stroke symptoms than the general population $(\mathrm{p}<0.01$, table 1$)$; there was no difference to the at risk group. Commonly cited symptoms were weakness and speech disturbance. Age, less than or greater than 75 years, made no difference to the level of stroke symptom knowledge in both the at risk $\left(\chi^{2}=0.05\right.$, $\mathrm{df}=1, \mathrm{p}=0.6)$ and general population $\left(\chi^{2}=0.29, \mathrm{df}=1\right.$, $\mathrm{p}=0.6$ ) groups. Most stated that stroke is always an emergency (at risk: 85\% (11.1); general population: 92.3\% (8.3)). In contrast, $23 \%$ (13) of medically trained nurses said that stroke was an emergency only occasionally. Most people said they would call an ambulance rather than the GP in the event of a stroke $(\mathrm{p}<0.01$, table 2$)$.

Table 1 Identification of stroke symptoms and risk factors by the different groups

\begin{tabular}{|c|c|c|c|c|}
\hline & \multicolumn{2}{|c|}{$\begin{array}{l}\text { Number of stroke } \\
\text { symptoms } \\
\text { identified }\end{array}$} & \multicolumn{2}{|c|}{$\begin{array}{l}\text { Number of stroke } \\
\text { risk factors } \\
\text { identified }\end{array}$} \\
\hline & Median & IQR & Median & IQR \\
\hline Stroke patients & N/A & N/A & $0 \dagger$ & 1 \\
\hline At risk & 2 & 1 & 1 & 0.75 \\
\hline $\begin{array}{l}\text { General } \\
\text { population }\end{array}$ & 2 & 1 & 1 & 1.75 \\
\hline $\begin{array}{l}\text { Medically trained } \\
\text { nurses }\end{array}$ & $2^{\star}$ & 1.5 & $2 \ddagger$ & 1.75 \\
\hline
\end{tabular}

*Medically trained nurses identified significantly more stroke symptoms than the general population group (KruskalWallis and Mann-Whitney $U, p=0.006$ ).

†Stroke patients identified significantly fewer risk factors for stroke than the other groups (Kruskal-Wallis and MannWhitney $U, p<0.05$ ).

$\ddagger$ Medically trained nurses identified significantly more stroke risk factors than the other groups (Kruskal-Wallis and MannWhitney $U, p<0.01$ ).
Table 2 Help that would be sought in the event of a stroke

\begin{tabular}{llll}
\hline & GP & Ambulance & A\&E \\
\hline $\begin{array}{l}\text { At risk } \\
\begin{array}{l}\text { General } \\
\text { population }\end{array}\end{array}$ & $27.5(13.8)$ & $72.5(13.8)$ & $0(0)$ \\
$\begin{array}{l}\text { Medically } \\
\text { trained nurses }\end{array}$ & $17.5(11.8)$ & $90(12.4)$ & $2.5(4.8)$ \\
\hline
\end{tabular}

A\&E, Accident and Emergency department.

Data are percentage $(\mathrm{Cl})$.

\section{Recognition of stroke by patients and action taken following their stroke}

Forty per cent (15.2) of stroke patients correctly identified the diagnosis. Only $32 \%$ (14.8) of those with risk factors remembered being told they were at risk. However, these patients were no more likely to recognise that they were having a stroke than those who did not know that they were at risk for stroke $\left(57 \%\right.$ (36.7) $v 35.5 \%(16.8) ; \chi^{2}=1.13, \mathrm{df}=1$, $\mathrm{p}=0.29)$. Illness delay ranged from 5 minutes to nearly 6 days, with a median of 30 minutes (table 3). Medical help was sought by the patient in $15 \%$ (11.8) of cases, a family member in $67.5 \%$ (14.5), and a member of the public in $17.5 \%$ (11.8). When patients recognised they were having a stroke, illness delay was shorter and patients were more likely to call for help themselves. Neither of these differences was significant $\left(\mathrm{p}=0.79\right.$ and $\chi^{2}=0.03, \mathrm{df}=1, \mathrm{p}=0.87$ respectively). The general practitioner was the point of access to medical services in $80 \%$ (12.4) of cases (table 3 ). This is significantly different from the planned course of action in the non-stroke groups $\left(\chi^{2}=49, \mathrm{df}=3, \mathrm{p}<0.001\right)$. Where the stroke was recognised by the patient or a family member, there was a trend towards it being more likely that an ambulance would be called $\left(\chi^{2}=0.74, \mathrm{df}=1, \mathrm{p}=0.39\right)$ (table 3).

\section{Knowledge of stroke risk factors}

Forty per cent (15.2) of stroke patients were able to name at least one major risk factor. Overall, stroke patients' knowledge of stroke risk factors was worse than in the other groups (table $1, \mathrm{p}<0.05$ ). There was a significant age effect among stroke patients with regard to knowledge of stroke risk factors. Fifty-seven per cent of stroke patients aged $<75$ years were able to list at least one stroke risk factor compared with $19 \%$ aged $\geqslant 75$ years $\left(\chi^{2}=4.94, \mathrm{df}=1\right.$, $\mathrm{p}=0.026)$. Knowledge of stroke risk factors by stroke patients was better in patients who recognised they were having a stroke, although not reaching significance $(56.25 \% \mathrm{v}$ $29.2 \%, \chi^{2}=2.93, \mathrm{df}=1, \mathrm{p}=0.8$ ). Among stroke patients, the most commonly mentioned risk factors were smoking and

Table 3 Time from onset of symptoms to when help was sought and the nature of medical help sought (per cent) by patients with a cerebral ischaemic event

\begin{tabular}{lllll}
\hline & $\begin{array}{l}\text { Time (mins) } \\
\text { taken from } \\
\text { onset of } \\
\text { symptoms to } \\
\text { seeking help, }\end{array}$ & & Nature of medical help sought \\
median (IQR) & GP & Ambulance & A\&E \\
\hline Overall & 30 (10 to 161) $80(12.4)$ & $17.5(11.8)$ & $5(6.7)$ \\
$\begin{array}{l}\text { Stroke recognised } \\
\text { Stroke not } \\
\text { recognised }\end{array}$ & 25 (10 to 83) $75(13.4)$ & $25(13.4)$ & $0(0)$ \\
\hline
\end{tabular}

GP, general practitioner; A\&E, Accident and Emergency department. Data are \% (Cl) unless otherwise stated. 


\begin{tabular}{|c|c|c|c|c|c|c|}
\hline Risk factors & Stroke patients & At risk & $\begin{array}{l}\text { General } \\
\text { population }\end{array}$ & Nurses & $\chi^{2}$ & $\mathrm{p}$ \\
\hline Smoking & $22.5(12.9)$ & 40 (15.2) & $50(15.5)$ & 47.5 (15.5) & 7.7 & 0.052 \\
\hline Hypertension & $20(12.4)$ & $32.5(14.5)$ & 27.5 (13.8) & 75 (13.4) & 30.9 & $<0.01$ \\
\hline Cholesterol & $10(9.3)$ & 12.5 (10.2) & $7.5(8.2)$ & 40 (15.2) & 19.0 & $<0.01$ \\
\hline $\mathrm{AF}$ & 7.5 (8.2) & $0(0)$ & $0(0)$ & $2.5(4.8)$ & 6.1 & 0.1 \\
\hline Diabetes & $5(6.7)$ & $2.5(4.8)$ & $0(0)$ & $7.5(8.2)$ & 3.5 & 0.32 \\
\hline Old age & $0(0)$ & $2.5(4.8)$ & $0(0)$ & $7.5(8.2)$ & 6.1 & 0.1 \\
\hline $\begin{array}{l}\text { Ischaemic heart } \\
\text { disease/CVD }\end{array}$ & $0(0)$ & $10(9.3)$ & 15 (11.1) & $7.5(8.2)$ & 6.3 & 0.1 \\
\hline Stress & $17.5(11.8)$ & 20 (12.4) & $35(14.8)$ & $5(6.7)$ & & \\
\hline Poor diet & $17.5(11.8)$ & 30 (14.2) & 27.5 (13.8) & 15 (11.1) & & \\
\hline Overexertion & $10(9.3)$ & $0(0)$ & 12.5 (10.2) & $0(0)$ & & \\
\hline Thick blood & $7.5(8.2)$ & $7.5(8.2)$ & $2.5(4.8)$ & $0(0)$ & & \\
\hline Family history & $5(6.7)$ & $10(9.3)$ & $7.5(8.2)$ & $17.5(11.8)$ & & \\
\hline Overweight & $5(6.7)$ & $22.5(12.9)$ & 32.5 (14.5) & $20(12.4)$ & & \\
\hline Alcohol excess & $5(6.7)$ & 20 (12.4) & $10(9.3)$ & $0(0)$ & & \\
\hline Fast heart rate & $5(6.7)$ & $0(0)$ & $0(0)$ & $0(0)$ & & \\
\hline Inactivity & $2.5(4.8)$ & $5(6.7)$ & 12.5 (10.2) & $5(6.7)$ & & \\
\hline Heart valve disease & $2.5(4.8)$ & $0(0)$ & $0(0)$ & $0(0)$ & & \\
\hline
\end{tabular}

hypertension $(20 \%)$ (table 4 ). No patient recognised that ischaemic heart disease is a risk factor for stroke, despite this being present in $22.5 \%$ of cases. Only $20 \%$ of stroke patients with atrial fibrillation correctly identified this as a risk factor for stroke (table 5). Stroke patients with a background of diabetes, hypertension, or smoking were more likely to identify their risk factors for stroke compared with patients with high cholesterol or atrial fibrillation (table 5).

In the at risk group, the percentage of people with a risk factor who were unaware of its significance for stroke was: atrial fibrillation $100 \%$; diabetes $90 \%$; ischaemic heart disease or previous cerebrovascular event $86 \%$; and hypertension $57 \%$ (table 5). However, patients with hypertension and smoking were significantly more likely to identify these as risk factors. None of the stroke patients, and only a third of the at risk group who had suffered a previous stroke or TIA recognised this as being a risk factor for further stroke.

Overall, medically trained nurses listed significantly more risk factors for stroke than any of the other groups $(\mathrm{p}<0.01$, table 1). However, only $25 \%$ (13.4) were able to list three or more risk factors. These were most likely to be smoking, hypertension, and high cholesterol, of which they were significantly more aware than the other non-stroke groups (table 4). However, nurses' ability to list atrial fibrillation, diabetes, or previous history of cerebral ischaemia as risk factors was no better than that of the general population or at risk groups (table 4 ).
Twenty two per cent of stroke patients and 33\% of at risk patients remembered having their risk of stroke discussed with them. These patients were no more likely to list correctly one or more risk factors $\left(\chi^{2}=0.03, \mathrm{df}=1, \mathrm{p}=0.86\right.$; and $\chi^{2}=1.6, \mathrm{df}=1, \mathrm{p}=0.95$ respectively). This is in keeping with the finding that only $12.5 \%$ of stroke patients and $7.5 \%$ of at risk patients cited a member of the medical profession as a source of information about stroke risk factors (table 6).

In each group, the main source of knowledge for both risk factors was personal or family experience (table 6). A similar pattern was found for source of knowledge about stroke symptoms (data not presented). Most nurses cited their training as their other main source of knowledge.

\section{DISCUSSION}

Public education campaigns should prompt early diagnosis of stroke, and by implication, earlier hospital admission. ${ }^{91-14}$ This study investigated stroke and stroke knowledge in part of Devon to identify local factors contributing to delay that could be targeted by an education programme to facilitate early hospital admission.

Knowledge of stroke in three non-stroke populations was good; about $90 \%$ listed at least one recognised stroke symptom, with no significant age effect, the at risk group matching the level of symptom knowledge of medically trained nurses. This exceeds previously published data of 40$56 \%,{ }^{13} 141721$ and may reflect recruitment of participants from

\begin{tabular}{|c|c|c|c|c|c|c|c|c|}
\hline \multirow[b]{2}{*}{ Risk factor } & \multicolumn{2}{|c|}{ Stroke patients } & \multicolumn{2}{|c|}{$\begin{array}{l}\text { (Compared with } \\
\text { those without RF) }\end{array}$} & \multicolumn{2}{|c|}{ At risk patients } & \multicolumn{2}{|c|}{$\begin{array}{l}\text { (Compared with } \\
\text { those without RF) }\end{array}$} \\
\hline & $\%$ with RF & $\begin{array}{l}\text { \% of those with } \\
\text { RF who listed it }\end{array}$ & $\chi^{2}$ & $p$ & \% with RF & $\begin{array}{l}\text { \% of those with } \\
\text { RF who listed it }\end{array}$ & $\chi^{2}$ & p \\
\hline HT & 45 (15.4) & $33.3(21.7)$ & 3.64 & 0.056 & 75 (13.4) & $43.3(17.7)$ & 6.42 & 0.01 \\
\hline DM & $15(11.1)$ & $33.3(37.7)$ & 11.9 & $<0.01$ & 27.5 (13.8) & ) $9.1(17.0)$ & 2.7 & 0.44 \\
\hline Smoker & 25 (13.4) & $60(30.4)$ & 10.75 & 0.01 & $10(9.3)$ & $100(0)$ & 6.67 & $<0.01$ \\
\hline Ex-Smoker & 30 (14.2) & $8.3(15.6)$ & 0.06 & 0.8 & 30 (14.2) & $41.7(27.9)$ & 0.06 & 0.8 \\
\hline & $17.5(11.8)$ & $14.3(25.9)$ & 0.17 & 0.67 & $62.5(15.0)$ & $16(14.4)$ & 0.75 & 0.39 \\
\hline $\mathrm{AF}$ & $25(13.4)$ & $20(24.8)$ & 3 & 0.08 & 15 (11.1) & $0(0)$ & 0 & 1 \\
\hline IHD or CVD & 45 (15.4) & $0(0)$ & 12.1 & $<0.01$ & 50 (15.5) & $15(15.6)$ & 0.11 & 0.99 \\
\hline
\end{tabular}




\begin{tabular}{|c|c|c|c|c|c|c|c|}
\hline \multirow[b]{2}{*}{ Group } & \multicolumn{7}{|c|}{ Source of knowledge } \\
\hline & $\begin{array}{l}\text { Personal } \\
\text { experience }\end{array}$ & $\begin{array}{l}\text { Family } \\
\text { experience }\end{array}$ & $\begin{array}{l}\text { Medical } \\
\text { services }\end{array}$ & Literature & Television & Advertising & Other \\
\hline Stroke & 20 & 2.5 & 12.5 & 15 & 7.5 & 0 & 15 \\
\hline At risk & 37.5 & 17.5 & 7.5 & 27.5 & 5 & 0 & 10 \\
\hline General & 32.5 & 20 & 7.5 & 2.5 & 12.5 & 2.5 & 7.5 \\
\hline Nurses & 57.5 & 5 & 0 & 15 & 12.5 & 0 & 45 \\
\hline
\end{tabular}

hospital rather than the community. The majority (about $80 \%$ ) of the non-stroke population consider stroke an emergency and say they would call an ambulance in the event of a stroke. This figure is greater than the $52.7 \%$ found in another population based study, ${ }^{18}$ which may reflect a difference in knowledge base between the two populations.

Stroke patients' awareness that they were experiencing a stroke was poor. Only $40 \%$ identified that they were having a stroke. Other studies report lower percentages $\left(35 \%{ }^{19}\right.$ and $25 \%^{7}$ ). Stroke patients' use of acute medical services was also poor. A minority of patients called for medical help themselves (15\%), although there was a trend towards patients who knew they were having a stroke to seek medical help earlier. Even when they lived alone, patients tended to call a family member rather than medical services. A family member was the point of access to the medical services in $67.5 \%$ of cases.

The median time to calling for help was 30 minutes, which compares with 50 minutes to 4 hours found by others. ${ }^{6}$ The low figure suggests that family members, although possibly not recognising the signs of stroke, nevertheless quickly regard the event as requiring medical assistance. The GP was the initial point of contact with the medical services in $80 \%$ of cases; an ambulance was called in $17.5 \%$. This contrasts with the findings of $45 \%$ and $43 \%$ respectively in another UK based study, ${ }^{8}$ highlighting regional variations in accessing medical services, and demonstrating the importance of assessing local trends.

Access to medical services via the GP is associated with a significant increase in delay to reaching hospital. ${ }^{8}$ Calling an ambulance results in less delay. ${ }^{719}$ The present study demonstrates a trend towards an ambulance being called if the patient or family member recognised the event as being a stroke. Therefore, while self-recognition of stroke is not sufficient to result in rapid medical access, it remains an important first step. Alternatively, significant reductions in delay might be achieved if GPs sent patients directly into hospital via ambulance.

There was a significant discrepancy between awareness of stroke and behaviour of stroke patients: following their stroke most patients accessed medical services via a family member and GP, rather than calling an ambulance, which is what the majority of the non-stroke groups state they would do. The explanation for this may lie in the additional finding that good knowledge of stroke symptoms in the general and at risk populations is not sufficient to enable self diagnosis of stroke by patients. The response to specific symptoms is therefore different from that planned in event of a stroke. ${ }^{20}$ This suggests a need for targeted education to consolidate the link between symptoms and the diagnosis of stroke. Patients with stroke are disinclined to access medical services themselves. This may reflect denial of illness ${ }^{21}$ or a defence mechanism, ${ }^{22}$ and merits further investigation.

Education campaigns should target patients at risk of stroke. Self awareness of increased risk is therefore essential for success of an education programme. This study demonstrates that at risk patients have limited awareness of their increased risk, which has also been demonstrated by other studies. ${ }^{17} 1823$

Previous studies have investigated the source of knowledge about stroke and found that it is derived mainly from friends, relatives, or the media rather than from the medical services, the latter being quoted by only $8 \%$ of people in a community study, ${ }^{24}$ similar to the present finding of about $7.5 \%$. However, most risk factors require regular medical review, thereby providing an educational opportunity that is currently being missed. The finding that nurses did not cite important modifiable risk factors such as atrial fibrillation suggests that such patients may not be identified as being at risk by nurses during episodes of patient contact, resulting in further educational opportunities being missed.

An education programme could use GPs, nurses, or nurse specialists. With average consultation times of around 5 minutes, GPs may not be in a position to give good risk factor information and advice regarding stroke. Practice nurses could take on this role in vascular risk clinics. Interestingly, the stroke symptoms cited by nurses were more likely to include management difficulties on the ward, such as dysphagia and hypertension. This altered perception would need to be addressed if non-neurologically trained nurses were to be used in an education programme. Additionally it would have to be ensured that nurses used in such a programme were able to identify patients at risk by having a good knowledge of stroke risk factors. This would ensure that the opportunities for both therapeutic intervention and education are maximised.

The finding in this study that a smaller percentage of nurses regard stroke as always representing an emergency, and the observation that most GPs do not send stroke patients into hospital via ambulance, ${ }^{8}$ suggest a negative perception of treatment imperative within the medical profession. Any campaign will need to educate all professionals to address this issue.

Education programmes should:

- Reinforce the need for early admission to an acute stroke unit/hospital.

- Reinforce the link between occurrence of symptoms and the diagnosis of stroke.

- Emphasise the need to seek medical attention early.

- Emphasise the need to call an ambulance rather than the GP.

- Educate GPs to call an ambulance for patients with stroke.

This study is limited by its size and by the non-random selection of the groups. However, certain trends are suggested that could form the basis for a larger study to more clearly define local needs and provide a basis for planning further work to develop an education programme within the context of a local stroke service. An important group of patients that will have been excluded by the design of this study are those who have had a brief TIA at home and not sought medical 
advice. Nevertheless the data presented show that the general and at risk populations in Devon know about stroke but do not recognise it when it happens to them, thereby limiting their ability to take the action they know they should take in the event of a stroke. Additionally, the study highlights the need for further studies to assess psychological influences operating on patients and their families in the setting of acute stroke and the degree to which negative perception of treatment imperative impacts on this. Any preconceptions regarding stroke in potential educators would need to be explored prior to their used in an education programme.

\section{ACKNOWLEDGEMENTS}

We acknowledge the assistance of Dr D Wright with the statistical analyses.

\section{Authors' affiliations}

C Carroll, J Hobart, C Fox, L Teare, J Gibson, Department of Neurology, Derriford Hospital, Plymouth, UK

Competing interests: none declared

\section{REFERENCES}

1 Fontanarosa PB, Winker MA. Timely and appropriate treatment of acute stroke. JAMA 1998;279:1307-9.

2 SREAD Collaboration. The Italian guidelines for stroke prevention. Neurol Sci 2000;21:5-12.

3 De Keyser J, Sulter G, Langedijk M, et al. Management of acute ischaemic stroke. Acta Clinica Belgica 1999;54-5:302-5.

4 Heros RC, Camarata PJ, Latchaw RE. Brain Attack. Neurosurg Clin N Am 1997; 8: 135-44.

5 Ermani PG. Time of hospital presentation after stroke. A multicenter study in north-east Italy. Ital J Neurol Sci 1996;17:401-7.

6 Rosamond WD, Gorton RA, Hinn AR, et al. Rapid response to stroke symptoms: the delay in accessing stroke healthcare (DASH) study. Acad Emerg Med 1998;5:45-51.
7 Williams LS, Bruno A, Rouch D, et al. Stroke patients' knowledge of stroke. Influence on time to presentation. Stroke 1997;28:912-15.

8 Harraf F, Sharma AK, Brown MM, et al. A multicentre observational study of presentation and early assessment of acute stroke. BMJ 2002;325:17-20.

9 Daley S, Braimah J, Sailor S, et al. NINDS rt-PA study group. Education to improve stroke awareness and emergent response. J Neurosci Nurs 1997;29:393-6.

10 Stern EB, Berman M, Thomas JJ, et al. Community education for stroke awareness. An efficacy study. Stroke 1999;30:720-3.

11 Gupta A, Thomas P. Knowledge of stroke is lacking. BMJ 2002;325:392.

12 Collins DR, McCormack PME, O'Neill D. Poor knowledge of stroke can be improved by simple measures. BMJ 2002;325:392-3.

13 Hux K, Rogers T, Mongar K. Common perceptions about strokes. J Comm Health 2000;25:47-65.

14 Becker KJ, Fruin MS, Gooding TD, et al. Community-based education improves stroke knowledge. Cerebrovasc Dis 2001;11:34-43.

15 Jørgensen HS, Nakayama H, et al. Factors delaying hospital admission in acute stroke: The Copenhagen stroke study. Neurology 1996;47:383-7.

16 Hwang MY. Patient page: How do you know when someone is having a stroke? JAMA 1998;279:1324.

17 Pancioli AM, Broderick J, Kothari R, et al. Public perception of stroke warning signs and knowledge of potential risk factors. JAMA 1998;279: 1288-92.

18 Parahoo K, Thompson K, Cooper M, et al. Stroke: awareness of the signs, symptoms and risk factors - a population-based survey. Cerebrovasc Dis 2003;16:134-40.

19 Kothari R, Sauerbeck L, Jauch E, et al. Patient' awareness of stroke signs, symptoms, and risk factors. Stroke 1997;28:1871-5

20 Yoon SS, Heller RF, Levi C, et al. Knowledge of stroke risk factors, warning symptoms, and treatment among an Australian urban population. Stroke 2001;32:1926-30.

21 Yoon SS, Byles J. Perceptions of stroke in the general public and patients with stroke: a qualitative study. BMJ 2002;324:1065-8.

22 Pattenden J, Watt I, Lewin RJP, et al. Decision making process in people with symptoms of acute myocardial infarction: qualitative study. BMJ 2002;324:1006-9.

23 Samsa GP, Cohen SJ, Goldstein LB, et al. Knowledge of risk among patients at increased risk for stroke. Stroke 1997;28:916-21.

24 Cheung RTF, Li LSW, Mak W, et al. Knowledge of stroke in Hong Kong Chinese. Cerebrovasc Dis 1999;9:119-23. 